\title{
International Competition, Debt, and Uneven Development in a North-South Macroeconomic Model
}

\author{
TARO ABE
}

\begin{abstract}
This paper examines whether the intensification of international competition widens the gap between developing and developed economies. The intensification of international competition with an influential trade union in the North is known to lower the North's markup rate. This paper is unique because it points out that the intensification of international competition can widen the North-South gap when the Southern debt is taken into consideration. It also shows that the egalitarian policy in the North as influenced by trade unions is compatible with its international policy: relief of interest payments.
\end{abstract}

JEL classification: F19, O19

Keywords: North-South, Uneven Development, Debt

\section{INTRODUCTION}

Economic globalization that has gained much momentum recently has further intensified international competition. One contributing factor is the influx of new players from the newly industrialized economies; including the East Asian economies.

On the other hand, there are still many Southern economies that are left out in this international competition, all of which are still burdened with large debt. This paper examines whether the intensification of international competition widens the gap between the Northern economies and the debt-laden Southern economies. Figure 1 is a visual expression of the purpose of this paper.

As Adachi (1995) says, the intensification of international competition alters the monopoly power (markup rate) of the North. Normally, international competition tends to lower the North's monopoly power. However, it is possible that the monopoly power of the North will increase should the Northern economies have adjusted to the plunge in the wage rate due to the pressure of international competition. Therefore the change of the North's monopoly power as a result of the intense international competition is influenced by the power struggle between the union and management.

Taro Abe <taro-abe@ngu.ac.jp> is Associate Professor, Faculty of Economics, Nagoya Gakuin University, Atsuta-nishi-machi, Nagoya 456-0036, Japan.

Author's Note: I wish to thank Takeshi Nakatani, Tamotsu Nakamura, Noritsugu Nakanishi, and Peter Skott for their advice and suggestions. I also wish to thank Khoo ChunKeat for his help. Nonetheless, the author is responsible for any error in this paper. 
Fig. 1. Objective of this Paper

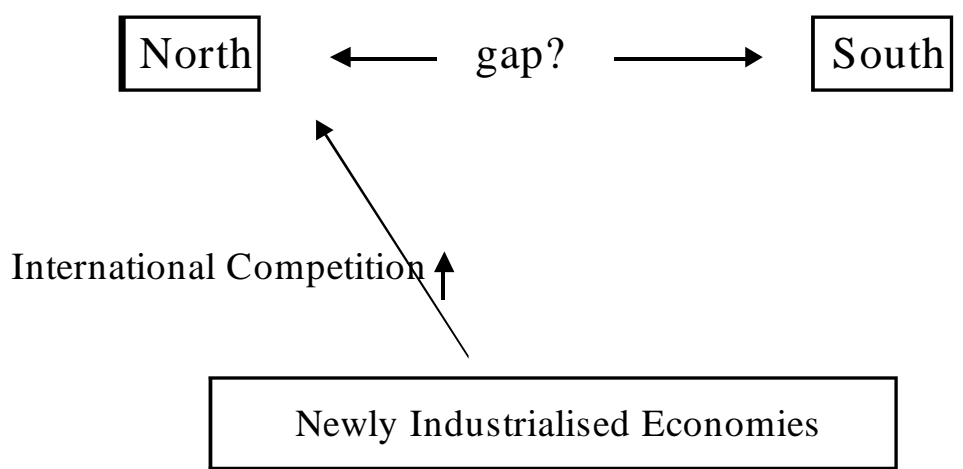

Dutt (1988) and Sarkar (1994) are works that discussed the relationship between the North's monopoly power and North-South economy. ${ }^{1}$ Dutt (1988) tries to build a model based on Bran's argument on the monopoly capital, in which Dutt (1988) introduces a Northern investment function that depends on the profit rate and the rate of capacity utilization. He showed that the increase in the North's monopoly power worsens the rate at which the capacity utilization of the North is utilized, the terms of trade of the South and the growth rates in both regions and widens the North-South gap. ${ }^{2}$ In contrast, Sarkar (1994) features a Northern investment function that depends only on profit rate. He showed that although the increase in the North's monopoly power does lower its rate of capacity utilization, it does not have any effect on the South's terms of trade as well as the growth rates in both regions. These works have one thing in common, namely the fact that they have a balance of trade equilibrium to begin with.

Hence, the increase in the North's monopoly power raises the demand for capital goods, which are produced only in the North, resulting a widening of the gap between North and South. However, a balance of trade equilibrium is certainly not a common phenomenon in the real world for there are countries in the South that are heavily indebted.

North-South models built with an interest in the Southern debt could be found in Dutt (1989) and Nakatani (1991). Both works discussed the conditions required to create a North-South economy with sustainable growth. Dutt (1989) takes the South's capital accumulation as an exogenous variable. Meanwhile, Nakatani (1991) introduces the South's investment function, considering that the ballooning debt in the South suppresses its capital accumulation. However, the imperfect competitive Northern economy found in Dutt (1988) or Sarkar (1994) is not found in Nakatani (1991).

Referring to this previous research, this paper introduces an independent investment function of the South, which takes the facts of the increasing debt and decreasing profit rate in the South suppressing its capital accumulation into consideration, and relieves the balance of trade equilibrium assumption proposed in Sarkar (1994).

${ }^{1}$ Adachi (1995) also writes on the relationship between the North's markup rate and the North-South economy but it will not be referred to in this paper because the research was done focusing not on the NorthSouth gap but on the terms of trade and capital flows were introduced into it.

${ }^{2}$ The South-North capital ratio is used as the gap index in Dutt (1988) and this paper will follow suit. 
Having such a model built, I will examine how the North's monopoly power influences the North-South gap. Based on this, we can discuss how the intensification of international competition influences the North-South gap, considering that the South is indebted.

\section{SARKAR (1994) MODEL}

An explanation of the Sarkar (1994) model is attempted in this section 2.1 outlines the model's basic structure and section 2.2 includes the arguments on how the change in the North's monopoly power influences the North-South gap.

\subsection{Basic Structure of the Model}

Northern Economy. An industrial good that acts as both a consumption and capital good, $Y$, is produced in the North. Denoting $K$ as the capital good used in the North, $u$ as the rate of capacity utilization and $\delta$ as a fixed technology coefficient, we can write the production function as

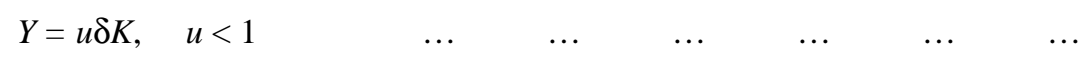

Denote $P$ as the price of the good in the North, $z$ as the markup rate, $W$ as the nominal wage rate and $b$ as the labor-output ratio, the North's pricing equation could be written as

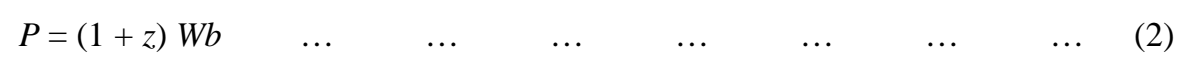

Furthermore, since the markup rate, z, carries information on the degree of monopoly power, using Equations (1) and (2), the North's profit rate, $r$, could be written as

$$
\begin{array}{lllllllll}
r=\frac{z}{1+z} \delta u & \ldots & \ldots & \ldots & \ldots & \ldots & \ldots & \ldots
\end{array}
$$

Assuming that $g$, the investment function of the North, is an increase function of its profit rate, $r$, we can conclude that

$$
g=\alpha_{1}+\alpha_{2} r, \quad \alpha_{1}>0, \quad \alpha_{2}>0
$$

$\alpha_{1}$ is the animal spirit of business entities.

Southern Economy. The South produces low technology or primary goods, using its labor and capital goods imported from the North. In other words, the Southern economies in this paper are referred to as those economies that are still incapable of producing capital goods. Denote $Y^{*}$ as the South's total output, $K^{*}$ as the total capital and assuming that the technology is fixed, we can express the South's production function as

$$
\begin{array}{llllllll}
Y^{*}=\alpha^{*} K^{*} & \ldots & \ldots & \ldots & \ldots & \ldots & \ldots & \ldots
\end{array}
$$

The South's output-capital ratio, $a^{*}$, is a constant. The real wage rate in the South, $V^{*}$, remains constant at a subsistence level because there is surplus labour.

Market Equilibrium. Both the North and South spend all of the wage income on consuming, save a certain fraction of the profit income and consume the rest of it. The North spends $m(0<m<1)$ of its total consumption expenditure on the Northern goods 
and the rest on Southern goods. The South spends all its wage income on Southern goods while spend $\mu(0<\mu<1)$ of its profit income on Northern goods and the rest on Southern goods. The price of Southern goods is denoted as $P^{*}$.

We can then express the consumption demand for Southern goods by the North as $(1-m)\{1+(1-s) z\} W b Y$, the consumption demand for Southern goods by the South itself as $P^{*} V^{*} a^{*} b^{*} K^{*}+(1-\mu)\left(1-s^{*}\right)\left(1-V^{*} b^{*}\right) P^{*} a^{*} K^{*}$. Hence, the market equilibrium of the Southern goods is given by

$$
(1-m)\{1+(1-s) z\} W b Y+P^{*} V^{*} a^{*} b^{*} K^{*}+(1-\mu)\left(1-s^{*}\right)\left(1-V^{*} b^{*}\right) P^{*} a^{*} K^{*}-P^{*} a^{*} K^{*}=0
$$

On the other hand, the consumption demand for Northern goods by the North is $m\{1+(1-s) z\} W b Y$ and that by the South is $\mu\left(1-s^{*}\right)\left(1-V^{*} b^{*}\right) P^{*} a^{*} K^{*}$. Denote $I$ and $I^{*}$ as the investment of North and South, respectively, the market equilibrium in the North is as follows because the investment demand for the Northern goods by both regions is $P I+P I^{*}$.

$$
m\{1+(1-s) z\} W b Y+\mu\left(1-s^{*}\right)\left(1-V^{*} b^{*}\right) P^{*} a^{*} K^{*}+P I+P I^{*}-P Y=0 \quad \ldots \quad \ldots
$$

Balance of Trade Equilibrium. The North imports consumption goods from the South while the South imports both consumption and investment goods from the North. Since the imports of Southern goods by the North is $(1-m)\{1+(1-s) z\} W b Y$ while the imports of Northern goods by the South is $\mu\left(1-s^{*}\right)\left(1-V^{*} b^{*}\right) P^{*} a^{*} K^{*}+P I^{*}$, the balance of trade equilibrium could be expressed as

$$
(1-m)\{1+(1-s) z\} W b Y-\mu\left(1-s^{*}\right)\left(1-V^{*} b^{*}\right) P^{*} a^{*} K^{*}-P I^{*}=0 \quad \ldots \quad \ldots
$$

Capital Accumulation. Define the North-South capital ratio as $h=\frac{K}{K^{*}}$ and since $g=\frac{I}{K}$ and $g^{*}=\frac{I^{*}}{K^{*}}$, the dynamic equation that shows the North-South capital accumulation is given by

$$
\begin{array}{llllllll}
\hat{h}=g-g^{*} & \ldots & \ldots & \ldots & \ldots & \ldots & \ldots & \ldots
\end{array}
$$

Intensive Form. Suppose the South's terms of trade is $p=\frac{P^{*}}{P}$, Equation (6) that expresses the market equilibrium of Southern goods could be rewritten as

$$
(1-m)\{1+(1-s) z\} \frac{\delta u h}{1+z}-\left\{s^{*}+\left(1-s^{*}\right) \mu\right\}\left(1-V^{*} b^{*}\right) a^{*} p=0 \ldots \quad \ldots \quad \ldots \quad
$$

Similarly, applying the balance of trade equilibrium Equation (8), Equation (7) that expresses the market equilibrium of Northern goods could then be rewritten as

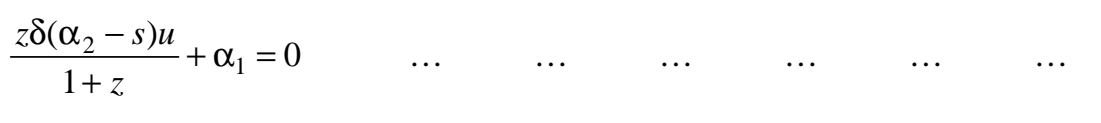


Applying Equation (3), the Northern investment function (Equation (4)) could be rewritten as

$$
g=\alpha_{1}+\alpha_{2} \frac{z}{1+z} \delta u \quad \ldots \quad \ldots \quad \ldots \quad \ldots \quad \ldots
$$

With the same spirit, applying Equation (6) and (8), the Southern capital accumulation rate could be expressed as

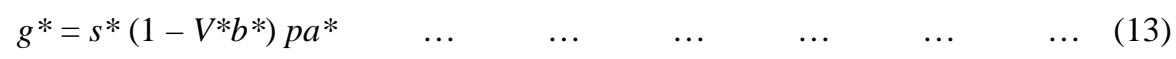

Adding Equation (9) will give us a total of equations and five endogenous variables respectively; namely $u, p, g, g^{*}$ and $h$, making this a closed system. Assuming $h$ is taking a certain value from Equation (9), p and u will be solved in (10) and (11), respectively. Hence, $g^{*}$ and $g$ are solved in (12) and (13), respectively.

\subsection{The North's Monopoly Power and Uneven Development}

We will see how the change in the North's monopoly power influences the NorthSouth gap in this section.

Short-run Equilibrium Analysis. Let's start with the short run analysis where the market equilibrium is achieved in both regions. This means Equation (9) will have to be removed for now and $h$ treated as an exogenous variable. ${ }^{3}$

From Equation (11) we get

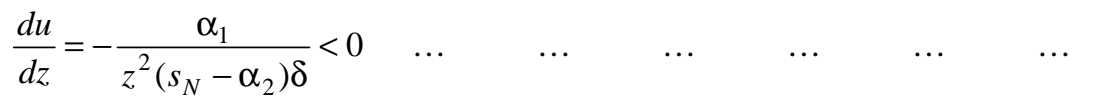

Apply this and an altered version of Equation (10) is what we have below

$$
\frac{d p}{d z}=-\frac{(1-m) \delta h}{\left\{s^{*}+\left(1-s^{*}\right) \mu\right\}\left(1-V^{*} b^{*}\right) a^{*}} \cdot \frac{-s u-\frac{\alpha_{1}\{1+(1-s) z\}(1+z)}{\left(s-\alpha_{2}\right) \delta z^{2}}}{(1+z)^{2}}<0 \quad \ldots
$$

This result is obtained because the rise in $z$ changes the type of received income from wage income with a high propensity for consumption to profit income with a low propensity for consumption, and as a result, worsens the total consumption demand in the North.

Long-run Equilibrium Analysis. Next we shall turn to the long run equilibrium when the capital accumulation rate of both regions is identical. ${ }^{4}$ We know that $\hat{h}=0$ so from Equations (9) and (10) to (13).

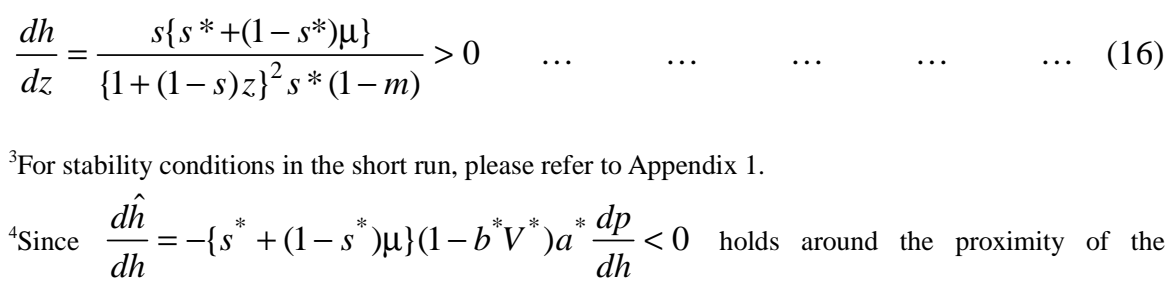

equilibrium, this system is therefore stable thereon. 
This means the North-South gap widens when the monopoly power of the North increases. It is so because the increase in the North's monopoly power raises the North's demand for capital goods, which are produced only in the North. The transfer from wage income to profit income as a result of the bigger monopoly power raises the demand for investment goods.

\section{INTERNATIONAL COMPETITION AND THE SOUTHERN DEBT}

What makes this section different from the last is that the Southern debt is taken into consideration here.

\subsection{Basic Structure of the Model}

Market Equilibrium. Denote $D$ as the South's debt measured in terms of the Northern good, with the interest rate on the debt as $i$.

The market equilibrium of the Southern and Northern goods, Equations (6) and (7), could be as follows because income transfer from the Southern profit income to a Northern one is done.

$$
\begin{aligned}
& (1-m)\{W b Y+(1-s)(z W b Y+i P D)\}+P^{*} V^{*} a^{*} b^{*} K^{*}+(1-\mu)\left(1-s^{*}\right) . \\
& \left\{\left(1-V^{*} b^{*}\right) P^{*} a^{*} K^{*}-i P D\right\}-P^{*} a^{*} K^{*}=0 \quad \ldots \quad \ldots \quad \ldots \\
& m\{W b Y+(1-s)(z W b Y+i P D)\}+\mu\left(1-s^{*}\right)\left\{\left(1-V^{*} b^{*}\right) P^{*} a^{*} K^{*}-i P D\right\}
\end{aligned}
$$

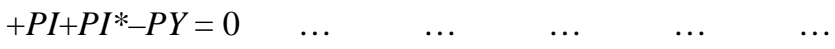

Capital Accumulation in the South. We introduce an independent investment function of the South. We assume that it is an increase function of its profit, $r^{*}$. Next, we consider the relationship between the debt and investment. The increasing debt of the South will worsen its credit rating as seen from the North. Therefore, cutting down on imports from the North would be a plausible way for the South to improve its trade deficit. Denote the debt capital ratio as $f=\frac{D}{K^{*}}$ and the South's investment function is given as

$$
g^{*}=\beta_{1}+\beta_{2} r^{*}-\beta_{3} f, \quad \beta_{1}>0, \quad \beta_{2}>0, \beta_{3}>0, \quad \ldots \quad \ldots \quad \ldots
$$

$\beta_{1}$ represents the Southern government's planned investment, etc.

Dynamic Equation of the Southern Debt. The increase in the South's debt, $\dot{D}$, equals its trade deficit plus the interest payment borne by the South. What we get is

$$
\dot{D}=\mu\left(1-s^{*}\right)\left(1-V^{*} b^{*}\right) p a^{*} K^{*}+I^{*}-(1-m)\{1+(1-s) z\} \frac{W}{P} b Y+i D \quad \ldots
$$

The dynamic equation of the South's debt capital ratio, $f$, is given as

$$
\begin{array}{llllllll}
\hat{f}=\hat{D}-g * & \ldots & \ldots & \ldots & \ldots & \ldots & \ldots & \ldots
\end{array}
$$


Intensive Form. Similar to that done in the last section, the market equilibriums of Southern and Northern goods, (17), (18), could be rewritten as

$$
\begin{gathered}
(1-m)\{1+(1-s) z\} \frac{\delta u h}{1+z}-\left\{s^{*}+\mu\left(1-s^{*}\right)\right\}\left(1-V^{*} b^{*}\right) a^{*} p+ \\
\text { if }\left\{(1-m)(1-s)-(1-\mu)\left(1-s^{*}\right)\right\}=0 \\
m\{1+(1-s) z\} \frac{\delta u h}{1+z}+\mu\left(1-s^{*}\right)\left(1-V^{*} b^{*}\right) a^{*} p+\left(\alpha_{1}+\alpha_{2} \frac{z}{1+z} \delta u\right) h+\beta_{1} \\
+\beta_{2}\left(1-V^{*} b^{*}\right) a^{*} p-\beta_{3} f-\delta u h+\left\{m(1-s)-\mu\left(1-s^{*}\right)\right\} \text { if }=0
\end{gathered}
$$

Equation (21), the dynamic equation of $f$, could be rewritten taking Equation (20) into consideration.

$$
\dot{f}=(1-f) g^{*}+\mu\left(1-s^{*}\right)\left(1-V^{*} b^{*}\right) a^{*} p-(1-m)\{1+(1-s) z\} \frac{\delta u h}{1+z}+i f \quad \ldots
$$

Putting together (9), (12) and (19) alongside (22) (24), we have a total of six equations and variables respectively, $u, p, g, g^{*}, h$ and $f$, closing this system. As for the determinant relations, assuming that $h$ and $f$ each take a certain value from (9) and (24), $p$ and $u$ are solved from (12), (14), (22) and (23).

\subsection{The Change in Monopoly Power of the North and Uneven Development}

We will examine how the change in the North's monopoly power influences the North-South gap in this section. ${ }^{5}$

Firstly, we will take a look at the short-run where market equilibrium is achieved in both regions. Next, based on findings obtained through short-run analyses, we will demonstrate how the North's mark up rate, $z$, affects $h$ in long-run equilibrium and unstable analysis. The economy becomes unstable when the interest rate on the debt is sufficiently large. The situation parallels the real world in developing countries. Long-run analyses will address both phases-stable and unstable.

Short-run Equilibrium Analysis. We are going to discard both (9) and (24) for now and take both $h$ and $f$ as exogenous variables. The next equation shows how $h, f$ and $z$ affect $p$ and $u .^{6}$

$$
p=p(h(+), f(-), z(-)), \quad u=u(h)(-), f(-), z(-)) \quad \ldots \quad \ldots \quad \ldots
$$

The increase in $h$ brings about two changes-a decreasing rate of capacity utilization in the North and improved terms of trade in the South. As for the increase in $\mathrm{f}$, it worsens the South's terms of trade while reducing the North's rate of capacity utilization due to the decrease in investment demand in the South. The increase in monopoly power in the North reduces its consumption demands as well as the rate of capacity utilization, and worsens the South's terms of trade.

\footnotetext{
${ }^{5}$ Sarkar (1997) assumes that the North's monopoly power is a increase function of the Southern terms of trade to consider the aspect of competitiveness between North and South. But we will work at this point in a different paper because we follow Sarkar (1994) model.

${ }^{6}$ Please refer to Appendix 2 for calculations.
} 
Long-run Equilibrium Analysis. Dynamic Equations (9) and (24) are required for this purpose. Using (12) and (19), (9) and (24) could be rearranged into two new dynamic equations.

$$
\begin{gathered}
\dot{h}=\left\{\alpha_{1}+\alpha_{2} \frac{z}{1+z} \delta u-\beta_{1}-\beta_{2}\left(1-V^{*} b^{*}\right) p a^{*}+\beta_{3} f\right\} h \quad \ldots \\
\dot{f}=(1-f)\left\{\beta_{1}+\beta_{2}\left(1-V^{*} b^{*}\right) p a^{*}-\beta_{3} f\right\}+\mu\left(1-s^{*}\right)\left(1-V^{*} b^{*}\right) p a^{*} \\
-(1-m)\{1+(1-s) z\} \frac{\delta u h}{1+z}+i f
\end{gathered}
$$

From Equations (26) and (27), we get $^{7}$

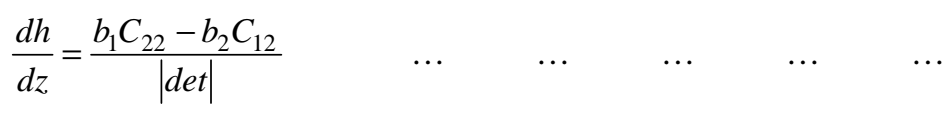

We direct our attention to the interest rate. ${ }^{8}$ If

$$
i<\beta_{1}-\beta_{3} f+\beta_{3}(1-f)+\frac{(1-m)\left[\beta_{3}\left\{(1-f) \beta_{2}-s^{*}\right\}+\beta_{2}\left(\alpha_{1} h+\beta_{1}-\beta_{3} f\right)\right]}{A}, \frac{d h}{d z}>0 .
$$

But if

$i>\beta_{1}-\beta_{3} f+\beta_{3}(1-f)+\frac{(1-m)\left[\beta_{3}\left\{(1-f) \beta_{2}-s^{*}\right\}+\beta_{2}\left(\alpha_{1} h+\beta_{1}-\beta_{3} f\right)\right]}{A}, \frac{d h}{d z}<0$.

That is to say, when the international monetary market is tight, the increase in the North's monopoly power decreases the North-South gap, and vice versa.

Next, we use some graphs. Figure 2 illustrates the phase diagram when the international monetary market is not tight or interest payments are reduced. The increase

\section{Fig. 2. When the International Monetary Market is not Tight (Equilibrium Analysis)}

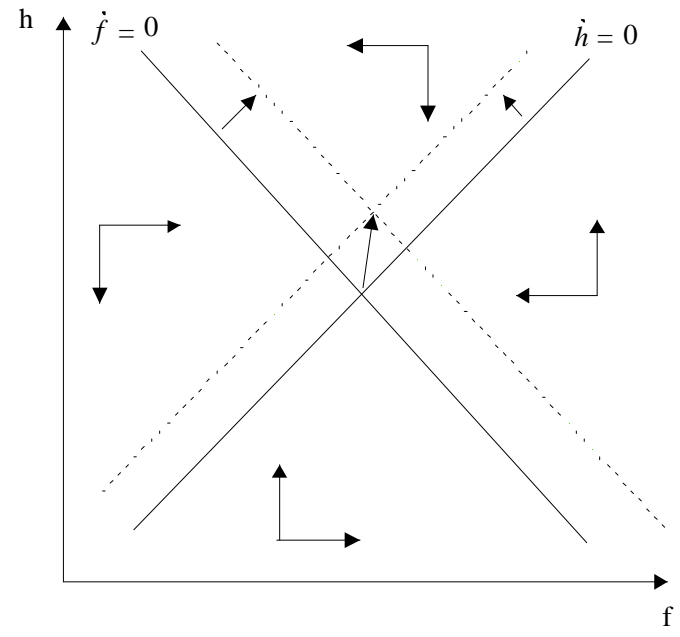

${ }^{7}$ Please refer to Appendix 3 for stability conditions and calculations in the long-run equilibrium. ${ }^{8}$ Incidentally, a sign of $\frac{d f}{d z}$ is undecided, and the result is not dependent on interest rate. 
in $z$ brings about decreasing imports in both regions because of the decrease in the rate of capacity utilization in the North and the terms of trade in the South. Thus, the Northern balance of trade improves because decreasing imports in the North are larger than in the South, hence the profit rate in the North increases. So the $\dot{h}=0$ curve shifts to the top left. On the other hand, the the $\dot{f}=0$ curve shifts to the top right to adjust to the improvement in the Northern balance of trade. Therefore we found that the increase of $z$ brings about the increase of $h$.

Figure 3 illustrates the phase diagram when the international monetary market is tight. The point different from Figure 2 is that the $\dot{f}=0$ curve shifts to the top left when $z$ increases. In other words, the increase in the Northern trade surplus brings about a decrease in $f$, because interest payments is large. We also point out that $\frac{d h}{d z}<0$ becomes more probable as the inclination of the $\dot{f}=0$ curve becomes more steep in Figure 3.

Long-run Unstable Analysis. We perform this analysis using Equations (26) and (27). The phase diagram of the unstable case is depicted in Figure $4 .^{9}$

The increase in $z$ shifts the $\dot{h}=0$ and $\dot{f}=0$ curves to the upper left because the Northern net export increases (Figure 5).

The increase in the Northern net export increases $g$ and decreases $f$. Once $f$ increases, it does so rapidly because the interest rate is extremely high. Therefore, $g *$ continues to decrease. In this way, $h$ increases with increasing $f$ from beginning to end. In this explosive path, the South can refuse to make interest payments for some time or repudiate its debt. ${ }^{10}$

\section{Fig. 3. When the International Monetary Market is Tight (Equilibrium Analysis)}

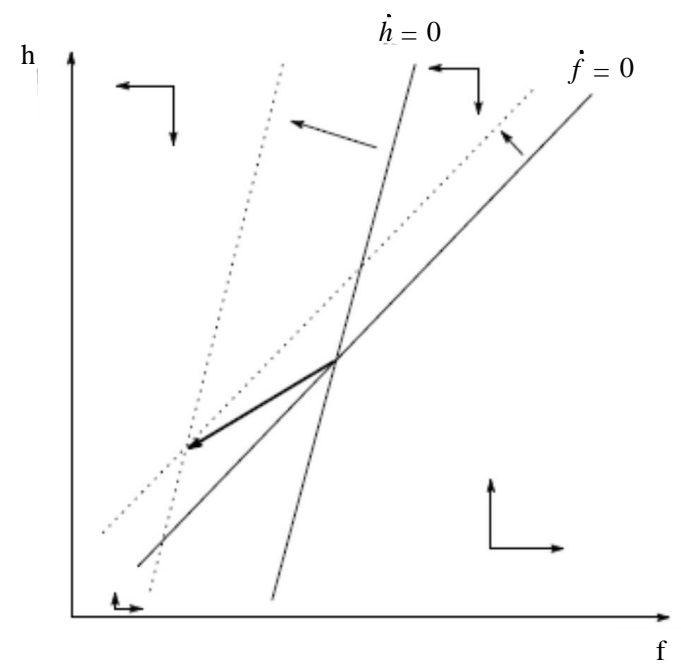

${ }^{9}$ In this case, $|\operatorname{det}|<0$ because the interest rate on the debt is sufficiently large.

${ }^{10}$ This result depends on the linear investment function of $f$ in the South, (19). Our paper does not address this problem. 
Fig. 4. The Unstable Phase Diagram

h

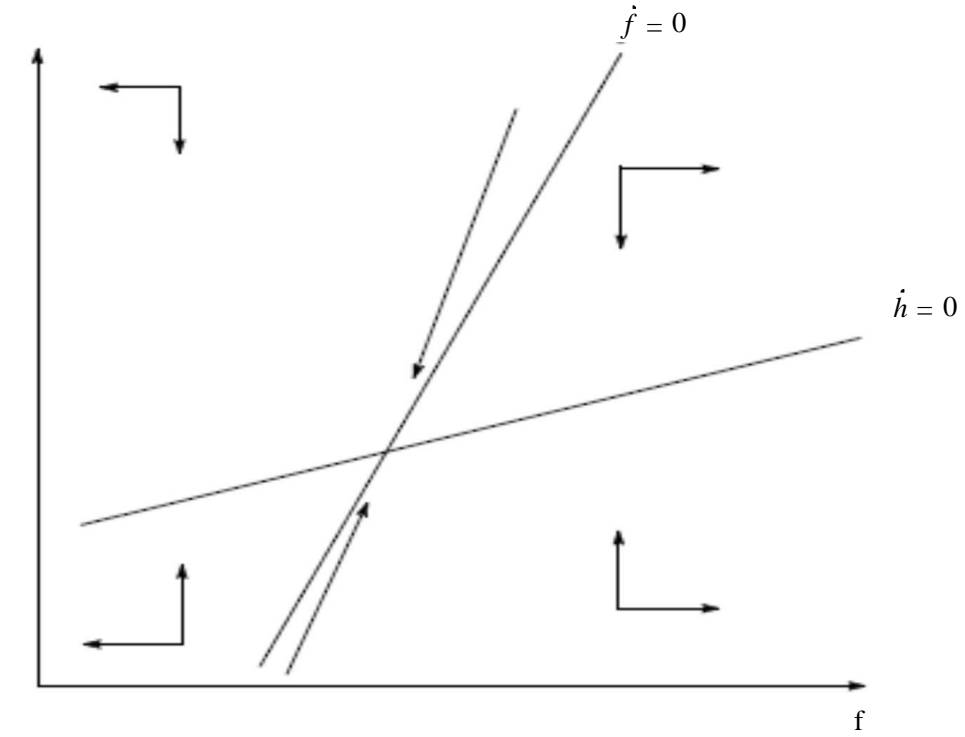

Fig. 5. When $z$ Increases (Unstable Analysis)

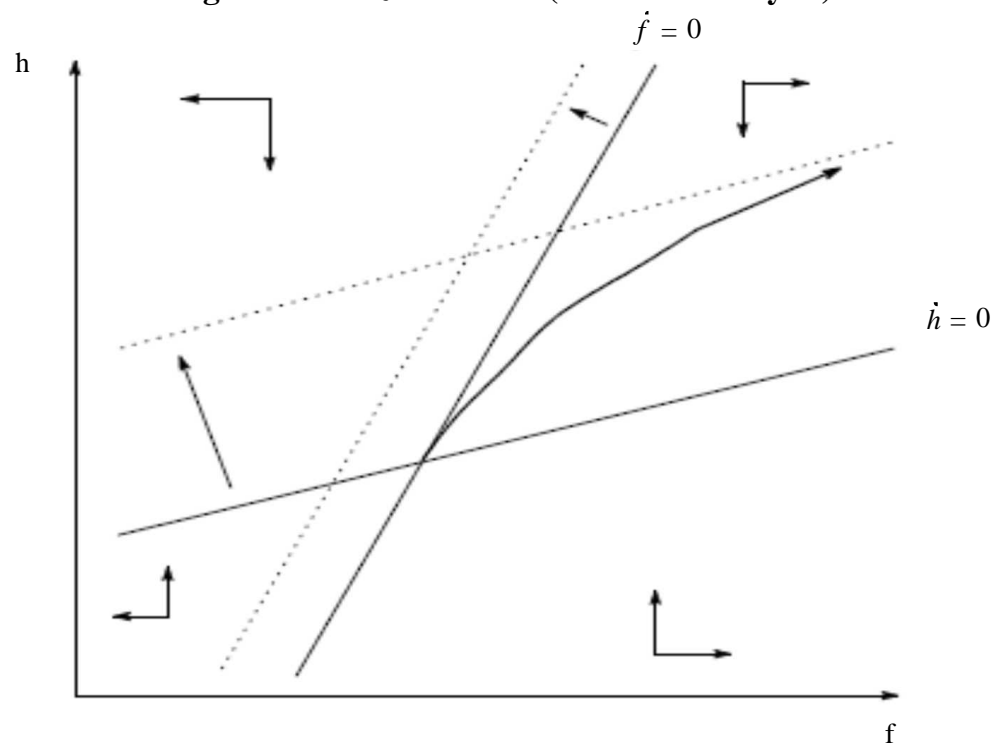

\section{CONCLUSION}

We have analyzed how the change in the North's monopoly power influences the North-South gap. The model featured in this paper is one that acknowledges the existence of Southern debt and accounts for its effect on the Southern investment. To date, it is concluded that the increase in the North's monopoly power will widen the North-South gap, as can be shown in Sarkar (1994) model, in which a balance of trade equilibrium is assumed. This paper, however, illustrates the possibility of a narrowing North-South gap 
when the interest rate on the South's debt is sufficiently high in equilibrium analysis. This result is obtained in a world without a balance of trade equilibrium, meaning that the reduction in the South's imports, in turn, reduces its debt and, as a result, promotes capital accumulation. Conversely, when the North's monopoly power is reduced, the North-South gap will definitely narrow when the balance of trade equilibrium does exist, however, a widening North-South gap is possible within the framework of this paper.

Noticing the polarization of union-management in the North, we can conclude the following. In a scenario where the South has no debt and the balance of trade equilibrium is in place, assuming that the union labor in the North is sufficiently influential, the monopoly power of the North will decrease and the North-South gap will definitely narrow when international competition intensifies. On the other hand, in a scenario where the South is indebted and negatively influences its growth thereon, it is necessary for the interest rate on the South's debt to be sufficiently low in order to narrow the North-South gap in the stable phase, with the assumption that international competition intensifies along with an influential union labor in the North.

In the unstable phase with the above-mentioned assumption, the gap continues to narrow and finally reaches the point at which $f=0$ (Figure 6). At that time, the debt problem in the South vanishes. The following effect reflects this result. When the North's monopoly power is reduced, its net export decreases. Then $\mathrm{f}$ decreases and subsequently continues to decrease because the interest payments decrease greatly from the high interest rate. As $f$ decreases, the interest payments will decrease according to the interest rate. A higher interest rate will further reduce the interest payments.

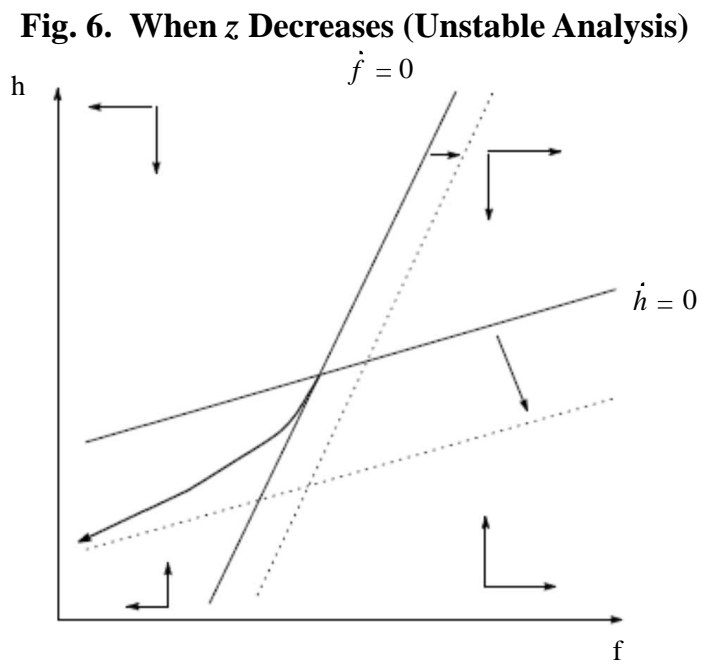

Therefore, what makes this paper unique is that it illustrates that when taking the Southern debt problem into consideration, the way in which the intensified international competition influences the North-South gap differs from the case in which a balance of trade equilibrium is assumed thereon.

From the results described above we can obtain some implications regarding the egalitarian policy. In the unstable phase, the decrease of the North's monopoly power decreases the gap. This result does not mean that relief of payments is not needed: other 
factors can widen it and exacerbate the debt problem in the unstable phase. In the stable phase with the higher interest rate, the decrease of the North's monopoly power widens the gap. However, in the case of the lower interest rate, we obtain the opposite result. Consequently, we showed that the egalitarian policy in the North from the influential trade union is compatible with its international policy: relief of interest payments.

We must remember that our result depends on the specification of parameters, as we said in Appendix 2, and we don't introduce the international monetary sector into this paper. On top of that, further empirical research has to be done on how the intensification in international competition influences the monopoly power of the North. These shall be left for future studies. 


\section{APPENDIX 1}

Take $h$ as exogenously given, based on (10) and (11), the adjustment equation of terms of trade and the rate of capacity utilization, $p$ and $u$, are given as

$$
\begin{aligned}
& \dot{p}=(1-m)\{1+(1-s) z\} \frac{\delta u h}{1+z}-\left\{s^{*}+\left(1-s^{*}\right) \mu\right\}\left(1-V^{*} b^{*}\right) a^{*} p \quad \ldots \quad \ldots
\end{aligned}
$$

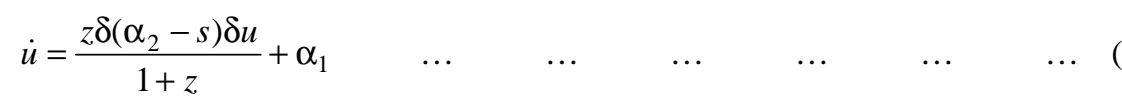

The right hand side of both equations illustrates a surplus in demand. Linearly approximate this dynamic equation at its equilibrium value $\left(p_{e}, u_{e}\right)$ and we will obtain the following Jacobians.

$$
\begin{array}{cc}
a_{11}=-\left\{s^{*}+\left(1-s^{*}\right) \mu\right\}\left(1-b^{*} V^{*}\right) a^{*} & a_{12}=(1-m)\{1+(1-s) z\} \frac{\delta u}{1+z} \\
a_{21}=0 & a_{22}=\frac{\delta\left(\alpha_{2}-s\right) z}{1+z}
\end{array}
$$

We now know this is stable because if $\alpha_{2}<s$ then trace $<0$ hence $\mid$ det $\mid>0$.

\section{APPENDIX 2}

We assume that $\mu=m$ and $s=s^{*}$ as a special case in Dutt (1989) because we don't pay attention to the effect on income distribution in the short term by interest payments. Take $h$ and $f$ as exogenously given, based on (22) and (23), the adjustment equation of the terms of trade and the rate of capacity utilisation, $p$ and $u$, are given as

$$
\begin{aligned}
& \dot{p}=(1-m)\{1+(1-s) z\} \frac{\delta u h}{1+z}-\left\{s^{*}+\left(1-s^{*}\right) \mu\right\}\left(1-V^{*} b^{*}\right) a^{*} p \quad \ldots \\
& \dot{u}=m\{1+(1-s) z\} \frac{\delta u h}{1+z}+\left\{\mu\left(1-s^{*}\right)+\beta_{2}\right\}\left(1-V^{*} b^{*}\right) a^{*} p+\alpha_{1} h+\alpha_{2} \frac{z}{1+z} \\
& \begin{array}{llllll}
\delta u h+\beta_{1}-\beta_{3} f-\delta u h & \ldots & \ldots & \ldots & \ldots & \ldots
\end{array}
\end{aligned}
$$

The right hand side of both equations illustrates a surplus in demand. Linearly approximate these dynamic equations at their equilibrium value $\left(p_{e}, u_{e}\right)$ and we will obtain the following Jacobians:

$$
\begin{array}{ll}
b_{11}=-\left\{s^{*}+\left(1-s^{*}\right) \mu\right\}\left(1-b^{*} V^{*}\right) a^{*}<0 & b_{12}=(1-m)\{1+(1-s) z\} \frac{\delta h}{1+z}>0 \\
b_{21}=\left\{\mu\left(1-s^{*}\right)+\beta_{2}\right\}\left(1-V^{*} b^{*}\right) a^{*}>0 & b_{22}=\left\{-(1-m)(1+z)+\left(a_{2}-m s\right) z\right\} \frac{\delta h}{1+z}
\end{array}
$$

Suppose $\alpha_{2}<m s$, we can demonstrate that trace $<0$ and $|\operatorname{det}|>0$ because $b_{22}<0$, hence the stability conditions hold. Furthermore, using Equations (32) and (33), the effects of $h, f$ and $z$ on $p$ and $u$ are given by

$$
\frac{\vartheta p}{\vartheta h}=\frac{-(1-m)\{1+(1-s) z\} \frac{\delta h}{1+z} \cdot \frac{\delta h}{1+z}\left\{-(1-m)(1+z)+\left(\alpha_{2}-m s\right) z\right\}}{|\operatorname{det}|}
$$




$$
\begin{aligned}
& +\frac{\left\{\mu\left(1-s^{*}\right)+\beta_{2}\right\}\left(1-V^{*} b^{*}\right) a^{*}\{(1+z)(1-m)+s m z\} \frac{\delta u}{1+z}}{|\operatorname{det}|}>0 \quad \ldots \\
& \frac{\vartheta u}{\vartheta h}=\frac{s^{*}\left(1-V^{*} b^{*}\right) a^{*}\left[m\{1+(1-s) z\} \frac{u \delta}{1+z}+\alpha_{1}+\alpha_{2} \frac{z}{1+z} \delta_{u}-\delta u\right]}{|\operatorname{det}|} \\
& +\frac{\mu\left(1-s^{*}\right)\left(1-V^{*} b^{*}\right) a^{*}\left[\{1+(1-s) z\} \frac{\delta u}{1+z}+\alpha_{1}+\alpha_{2} \frac{z}{1+z} \delta u-\delta u\right]}{|\operatorname{det}|}<0 \quad \ldots \quad \ldots
\end{aligned}
$$

$$
\frac{\vartheta p}{\vartheta f}=\frac{-\beta_{3}(1-m)\{1+(1-s) z\} \frac{\delta h}{1+z}}{|\operatorname{det}|}<0 \quad \ldots \quad \ldots \quad \ldots
$$

$$
\frac{\vartheta u}{\vartheta f}=\frac{-\left\{s^{*}+\left(1-s^{*}\right) \mu\right\}\left(1-V^{*} b^{*}\right) a^{*} \beta_{3}}{|\operatorname{det}|}<0 \quad \ldots \quad \ldots \quad \ldots \quad \ldots \quad \ldots
$$

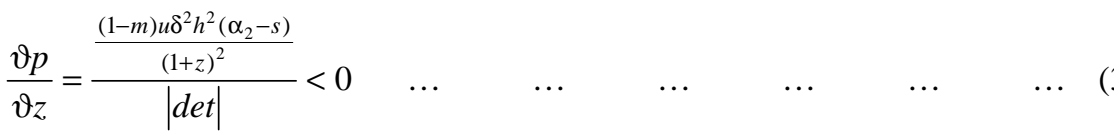$$
\frac{\vartheta u}{\vartheta z}=\frac{\left(1-V^{*} b^{*}\right) a * \frac{u h \delta\left\{s^{*}\left(\alpha_{2}-m s\right)+\left(1-s^{*}\right) \mu\left(\alpha_{2}-s\right)-\beta_{2}(1-m) s\right\}}{(1+z)^{2}}}{|\operatorname{det}|}<0 \quad \ldots \quad \ldots
$$ 


$$
+\frac{\left(\alpha_{1} h+\beta_{1}-\beta_{3} f\right)(1-m)\{1+(1-s) z\}\left\{(1-f) \beta_{2}-s^{*}\right\}}{\left(1-s^{*}\right) \mu z\left(s-\alpha_{2}\right)+(1-m)(1+z)\left(s^{*}-\beta_{2}\right)-s^{*}\left(\alpha_{2}-m s\right) z+\beta_{2}(1-m) s z}
$$

Linearly approximate Equations (43) and (44) at their equilibrium $\left(h_{e}, f_{e}\right)$, we obtain the following Jacobians.

$$
\begin{aligned}
c_{11}= & \frac{\frac{-\left(\beta_{1}-\beta_{3} f\right) \alpha_{2} z\left\{s^{*}+\left(1-s^{*}\right) \mu\right\}}{\left(1-s^{*}\right) \mu z\left(s-\alpha_{2}\right)+(1-m)(1+z)\left(s^{*}-\beta_{2}\right)-s^{*}\left(\alpha_{2}-m s\right) z+\beta_{2}(1-m) s z}}{c_{12}=} \beta_{3} h-\frac{\left.\beta_{3}\left[\alpha_{2} z\left\{s^{*}+\left(1-s^{*}\right) \mu\right\}-\beta_{2} h(1-m)\{1+1-s) z\right\}\right]}{\left(1-s^{*}\right) \mu z\left(s-\alpha_{2}\right)+(1-m)(1+z)\left(s^{*}-\beta_{2}\right)-s^{*}\left(\alpha_{2}-m s\right) z+\beta_{2}(1-m) s z} \\
c_{21}= & \frac{\alpha_{1}(1-m)\{1+(1-s) z\}\left\{(1-f) \beta_{2}-s^{*}\right\}}{\left(1-s^{*}\right) \mu z\left(s-\alpha_{2}\right)+(1-m)(1+z)\left(s^{*}-\beta_{2}\right)-s^{*}\left(\alpha_{2}-m s\right) z+\beta_{2}(1-m) s z}<0 \\
c_{22}= & -\left(\beta_{1}-\beta_{2} f\right)-\beta_{3}(1-f)+i \\
& +\frac{(1-m)\{1+(1-s) z\}\left[-\beta_{3}\left\{(1-f) \beta_{2}-s^{*}\right\}-\beta_{2}\left(\alpha_{1} h+\beta_{1}-\beta_{3} f\right)\right]}{\left(1-s^{*}\right) \mu z\left(s-\alpha_{2}\right)+(1-m)(1+z)\left(s^{*}-\beta_{2}\right)-s^{*}\left(\alpha_{2}-m s\right) z+\beta_{2}(1-m) s z}
\end{aligned}
$$

We assume that $c_{11}<0$ and $c_{12}>0$.

Next we perform comparative statics on $z$. From Equations (43) and (44),

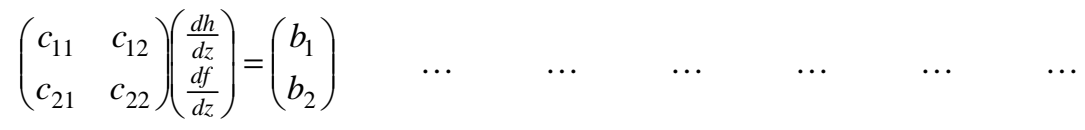

$$
\begin{aligned}
& b_{1}=\frac{-\left(\alpha_{1} h+\beta_{1}-\beta_{3} f\right)}{A^{2}} \cdot\left[\alpha_{2}\left\{s^{*}+\left(1-s^{*}\right) \mu\right\}(1-m)\left(s^{*}-\beta_{2}\right)\right. \\
& +\beta_{2} h m(1-s)\left(1-s^{*}\right) \mu z\left(s-\alpha_{2}\right) \\
& \left.+\beta_{2} h(1-m)^{2} s s^{*}+\beta_{2} h(1-m)\left\{\left(1-s^{*}\right) \mu\left(s-\alpha_{2}\right)-s^{*}\left(\alpha_{2}-m s\right)\right\}\right]<0 \\
& b_{2}=\frac{-\left(\alpha_{1} h+\beta_{1}-\beta_{3} f\right)(1-m)\left\{(1-f) \beta_{2}-s^{*}\right\}}{A^{2}} . \\
& \left\{\left(1-s^{*}\right) \mu\left(s-\alpha_{2}\right)+(1-m)\left(s^{*}-\beta_{2}\right) s+s^{*}\left(m s-\alpha_{2}\right)+\beta_{2}(1-m) s\right\}<0 \\
& A=\left(1-s^{*}\right) \mu z\left(s-\alpha_{2}\right)+(1-m)(1+z)\left(s^{*}-\beta_{2}\right)-s^{*}\left(\alpha_{2}-m s\right) z+\beta_{2}(1-m) s z
\end{aligned}
$$

Thus,

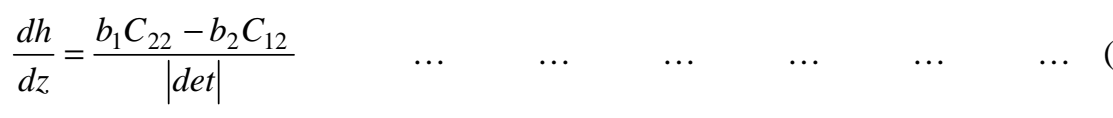


From trace $<0$, we get

$$
\begin{aligned}
& i<\beta_{1}-\beta_{3} f+\beta_{3}(1-f) \\
& +\frac{(1-m)\{1+(1-s) z\}\left[\beta_{3}\left\{(1-f) \beta_{2}-s^{*}\right\}+\beta_{2}\left(\alpha_{1} h+\beta_{1}-\beta_{3} f\right)\right]}{A} \\
& +\frac{\frac{\left(\beta_{1}-\beta_{3} f\right) \alpha_{2} z\left\{s^{*}+\left(1-s^{*}\right) \mu\right\}}{h}+\alpha_{1} \beta_{2}(1-m)\{1+(1-s) z\} h}{A} \\
& B=+\frac{\frac{\left(\beta_{1}-\beta_{3} f\right) \alpha_{2} z\left\{s^{*}+\left(1-s^{*}\right) \mu\right\}}{h}+\alpha_{1} \beta_{2}(1-m)\{1+(1-s) z\} h}{A}
\end{aligned}
$$

Also from $|\operatorname{det}|>0$, we get

$$
\begin{aligned}
& i<\beta_{1}-\beta_{3} f+\beta_{3}(1-f) \\
& +\frac{(1-m)\{1+(1-s) z\}\left[\beta_{3}\left\{(1-f) \beta_{2}-s^{*}\right\}+\beta_{2}\left(\alpha_{1} h+\beta_{1}-\beta_{3} f\right)\right]}{A} \\
& +C_{12} \cdot \frac{\alpha_{1}(1-m)\{1+(1-s) z\}\left\{(1-f) \beta_{2}-s^{*}\right\}}{-\frac{\left(\beta_{1}-\beta_{3} f\right) \alpha_{2} z\left\{s^{*}+\left(1-s^{*}\right) \mu\right\}}{h}-\alpha_{1} \beta_{2}(1-m)\{1+(1-s) h\}} \\
& C=C_{12} \cdot \frac{\alpha_{1}(1-m)\{1+(1-s) z\}\left\{(1-f) \beta_{2}-s^{*}\right\}}{\frac{\left(\beta_{1}-\beta_{3} f\right) \alpha_{2} z\left\{s^{*}+\left(1-s^{*}\right) \mu\right\}}{h}-\alpha_{1} \beta_{2}(1-m)\{1+(1-s) h\}}
\end{aligned}
$$

When $\frac{d h}{d z}<0$, we get

$$
\begin{aligned}
& i<\beta_{1}-\beta_{3} f+\beta_{3}(1-f) \\
& +\frac{(1-m)\{1+(1-s) z\}\left[\beta_{3}\left\{(1-f) \beta_{2}-s^{*}\right\}+\beta_{2}\left(\alpha_{1} h+\beta_{1}-\beta_{3} f\right)\right]}{A} \\
& +\frac{(1-m)\left\{(1-f) \beta_{2}-s^{*}\right\}\left\{\left(1-s^{*}\right) \mu\left(s-\alpha_{2}\right)\right.}{A F} \\
& +\frac{\left.(1-m)\left(s^{*}-\beta_{2}\right) s+s^{*}\left(m s-\alpha_{2}\right)+\beta_{2} s(1-m)\right\} C_{12}}{A F} \ldots \\
& F=\alpha_{2}\left\{s^{*}+\left(1-s^{*}\right) \mu\right\}(1-m)\left(s^{*}-\beta_{2}\right) \\
D=\frac{1}{A} & \cdot \frac{\left.(1-m)\left\{(1-f) \beta_{2}-s^{*}\right\}\left(1-s^{*}\right) \mu\left(s-\alpha_{2}\right)+(1-m)\left(s^{*}-\beta_{2}\right) s\right\} C_{12}}{F} \\
& +\frac{\left\{s^{*}\left(m s-\alpha_{2}\right)+\beta_{2} s(1-m)\right\} C_{12}}{F}
\end{aligned}
$$

From $B>0, C>0$ and $D<0$, we get $D<B, C$.

Thus there is i with Equations (47), (48) and (49).

Incidentally, when $i<\frac{1}{A} \cdot \frac{(1-m)\left\{(1-f) \beta_{2}-s^{*}\right\}\left\{\left(1-s^{*}\right) \mu\left(s-\alpha_{2}\right)+(1-m)\left(s^{*}-\beta_{2}\right) s+s^{*}\left(m s-\alpha_{2}\right)+\beta_{2} s(1-m)\right\} C_{12}}{\alpha_{2}\left\{s^{*}+\left(1-s^{*}\right) \mu\right\}(1-m)\left(s^{*}-\beta_{2}\right)+\beta_{2} h\left(1-s^{*}\right) \mu\left(s-\alpha_{2}\right)\{m(1-s) z+(1-m)\}+\beta_{2} h(1-m) s^{*}\left(s-\alpha_{2}\right)}$ the stability conditions hold. 


\section{REFERENCES}

Abe, T. (2005) The Northern Immigration Policy in a North-South Economy Model. The Pakistan Development Review 44:2, 197-218.

Adachi, H. (1995) Nanboku-Keizai no Seicyou to Koueki-Zyouken. In Keizo Nagatani and Kenichi Ishigaki (eds.) Kan-Taiheiyou-Keizai no Hatten to Nihon 23-50, KeisouShobo (in Japanese).

Dutt, A. K. (1988) Monopoly Power and Uneven Development: Baran Revisited. Journal of Development Studies 24, 161-76.

Dutt, A. K. (1989) Trade, Debt, and Uneven Development in a North-South Model. Metroeconomica 40, 211-233.

Ertürk, T. and W. Darity (2000) Secular Changes in the Gender Compositions of Employment and Growth Dynamics in the North and the South. World Development $28,1231-8$.

Findlay, R. (1980) The Terms of Trade and the Equilibrium Growth in the World Economy. American Economic Review 70, 291-9.

Khan, M. A. (1984) International Trade and Foreign Investment: A Model with Asymmetric Production. The Pakistan Development Review 22:4, 509-30.

Nakatani, T. (1991) Nanboku-Kezai no Seicyou to Boueki-Hukinkou. In Yoshiaki Nishimukai (eds.) Keizai-Hatten to Kan-Taiheiyou-Keizai 1-36, Kobe Daigaku Keizai Keiei Kenkyu-zyo (in Japanese).

Sarkar, P. (1994) North-South Terms of Trade and Growth: A Macroeconomic Framework on Kaldorian Lines. World Development 22, 1711-5.

Sarkar, P. (1997) Growth and Terms of Trade: A North-South Macroeconomic Framework. Journal of Macroeconomics 19, 117-33.

Taylor, L. (1981) South-North Trade and Southern Growth. Journal of International Economics 11, 589-602. 